\title{
BIOMARKERS OF KIDNEY INTEGRITY IN CHILDREN AND ADOLESCENTS WITH DENTAL AMALGAM MERCURY EXPOSURE: FINDINGS FROM THE CASA PIA CHILDREN'S AMALGAM TRIAL
}

\author{
James S. Woods ${ }^{a,{ }^{*}}$, Michael D. Martin ${ }^{b}$, Brian G. Leroux ${ }^{c, d}$, Timothy A. DeRouen ${ }^{c, d}$, Mario F. \\ Bernardo $^{e}$, Henrique S. Luis ${ }^{e}$, Jorge G. Leitão ${ }^{e}$, John V. Kushleika ${ }^{a}$, Tessa C. Rue ${ }^{c, d}$, and \\ Anna M. Korpak ${ }^{\mathrm{c}, \mathrm{d}}$ \\ aDepartment of Environmental and Occupational Health Sciences, University of Washington, \\ Seattle, Washington, USA \\ bDepartment of Oral Medicine, University of Washington, Seattle, Washington, USA \\ 'Department of Dental Public Health Sciences, University of Washington, Seattle, Washington, \\ USA \\ dDepartment of Biostatistics, University of Washington, Seattle, Washington, USA \\ eFaculdade de Medicina Dentaria, Universidade de Lisboa, Lisbon, Portugal.
}

\section{Abstract}

Mercury is toxic to the kidney, and dental amalgam is a source of mercury exposure. Few studies have evaluated the effects of dental amalgam on kidney function in a longitudinal context in children. Here, we evaluated urinary concentrations of glutathione S-transferases (GSTs) $\alpha$ and $\pi$ as biomarkers of renal proximal and distal tubular integrity, respectively, and albumin as a biomarker of glomerular integrity in children and adolescents 8-18 years of age over a 7 year course of dental amalgam treatment. Five hundred seven children, 8-12 years of age at baseline, participated in a clinical trial to evaluate the neurobehavioral and renal effects of dental amalgam in children. Subjects were randomized to either dental amalgam or resin composite treatments. Urinary GSTs $\alpha$ and $\pi$, albumin and creatinine concentrations were measured at baseline and annually on all subjects. Results were evaluated using linear regression analysis. GST- $\alpha$ concentrations were similar between treatment groups and in each sex and race (white vs nonwhite) group in each follow-up year. GST- $\pi$ levels tended upward over the course of follow-up by 4- to 6-fold. This increase was seen in all groups irrespective of treatment, race or gender. Females had GST- $\pi$ levels approximately twice those of males at all ages. Albumin concentrations were constant throughout the follow-up period and did not differ by treatment, although females had $39 \%$ higher albumin levels than males. Additionally, we found no significant effects of amalgam treatment on the proportion of children with microalbuminuria (>30 mg/g creatinine). These findings are relevant within the context of children's health risk assessment as relates to the safety

(C) 2008 Elsevier Inc. All rights reserved

*Author to whom page proofs should be sent: Department of Environmental and Occupational Health Sciences University of Washington 4225 Roosevelt Way NE, Suite 100 Seattle, WA 98105 Telephone: 206 685-3443 Fax: 206 685-4696 jwoods@u.washington.edu

Publisher's Disclaimer: This is a PDF file of an unedited manuscript that has been accepted for publication. As a service to our customers we are providing this early version of the manuscript. The manuscript will undergo copyediting, typesetting, and review of the resulting proof before it is published in its final citable form. Please note that during the production process errors may be discovered which could affect the content, and all legal disclaimers that apply to the journal pertain. 
of mercury exposure from dental amalgam on kidney function. These data also provide normative values for sensitive indices of renal functional integrity that may serve in the evaluation of children and adolescents with renal disorders.

\section{Keywords}

biomarker; kidney; mercury; amalgam; children

\section{INTRODUCTION}

The renal tubular system is comprised of several segments with highly specialized functions (Schmidt and Guder, 1976), each differentially sensitive to injury by drugs and environmental chemicals. The release of cytoplasmic proteins and other constituents into the urine following injury to tubular cells has long been clinically exploited to assess the site and severity of renal tubular damage associated with disease and toxicant exposures (Bernard and Lauwerys, 1991; Woods, 1996; Zhou et al., 2008). Among the proteins of longstanding utility in the assessment of renal injury are the glutathione S-transferases (GSTs) (Feinfeld et al., 1984; Sundberg et al., 1994), most of which are found in soluble form in the cytosolic fraction of tubular epithelial cells. In humans, two GSTs of particular interest as biomarkers of tubular damage are GST-alpha (GST- $\alpha$ ), which is localized to the proximal tubule (Bäckman et al., 1988; Campbell et al., 1991), and GST-pi (GST- $\pi$ ), found in epithelial cells of the distal tubule and the collecting ducts (Sundberg et al., 1994).

Of additional interest as a biomarker of renal function and tubular integrity is albumin, a low molecular weight plasma protein that is normally $99 \%$ reabsorbed by proximal tubular cells following filtration by the glomerulus. The concentration of albumin in the urine is commonly employed as a measure of both glomerular filtration and tubular reabsorptive capacity (Remuzzi and Bertani, 1998) and, more currently, as a biomarker of incipient tubulointerstitial damage associated with disease or nephrotoxicant exposure (Lambers Heerspink et al., 2006; Ohse et al., 2006).

Elemental mercury $\left(\mathrm{Hg}^{0}\right)$ is among the toxicants of particular concern in regard to tubular injury (Zalups, 2000). A prominent source of $\mathrm{Hg}^{0}$ exposure in humans is dental amalgam fillings, which are approximately $50 \%$ metallic mercury by weight. $\mathrm{Hg}^{0}$ vapor released from amalgam fillings in tooth surfaces is readily absorbed into the systemic circulation by inhalation (Berglund et al., 1988; Mackert and Berglund, 1997; Svare et al., 1981; Vimy and Lorscheider, 1985). Once absorbed, $\mathrm{Hg}^{0}$ undergoes biotransformation predominantly in erythrocytes to mercuric ion $\left(\mathrm{Hg}^{2+}\right)$, the ultimate mediator of mercury toxicity (Halbach and Clarkson, 1978; Magos et al., 1978). In humans and other mammals, the kidney represents a primary target organ in which $\mathrm{Hg}^{2+}$ accumulates after $\mathrm{Hg}^{0}$ exposure, with highest concentrations found in S-3 segment cells (pars recta) of the proximal tubule. The potential adverse effects of low-level $\mathrm{Hg}^{0}$ exposure from dental amalgam, particularly in children, remain a topic of continued debate (Brownawell et al., 2005; Clarkson and Magos, 2006).

Findings from two concurrently conducted clinical trials that were designed to evaluate the potential health consequences of prolonged $\mathrm{Hg}^{0}$ exposure from dental amalgam fillings in children have been recently reported (Bellinger et al., 2006; DeRouen et al., 2006). As part of one of those trials (DeRouen et al., 2006), we performed annual measurements of urinary GSTs and albumin concentrations in children between 9 and 18 years of age as an assessment of potential kidney injury associated with prolonged $\mathrm{Hg}^{0}$ exposure. Here we describe measures of urinary GSTs and albumin concentrations in children with and without amalgam fillings over the course of the trial. We also report age-related changes and race- 
and sex-related differences in these parameters in children and adolescents with and without amalgam treatment.

\section{MATERIALS AND METHODS}

\section{Description of the study population}

The children's cohort was derived from the recently completed Casa Pia clinical trial of the health effects of dental amalgam fillings in children (DeRouen et al. 2006). Subjects $(n=507)$ were boys and girls (54:46\%), 70\% white, aged 8-12 at inception, who were residents of the Casa Pia school system in Lisbon, Portugal. Subjects were initially randomized to mercury amalgam (treatment) or composite resin (control) dental treatment groups. The study protocol was approved by the institutional review boards at the University of Washington and the University of Lisbon. All parents or guardians gave written consent, and all children provided signed assent. Principal design and analytical issues involved in this trial (DeRouen et al., 2002) as well as principal outcome measures (DeRouen et al., 2006) have been reported.

\section{Procedures for urine collection and measures of urinary GSTs, albumin and creatinine}

Methods of urine collection for this study have been described (Woods et al., 2007). Concentrations of GSTs $\alpha$ and $\pi$ in urine samples were measured by enzyme immunoassay employing kits purchased from Biotrin USA (Cedarknolls, NJ, USA). The assay procedure is based on the sequential addition of sample, enzyme-conjugate and substrate to microtiter wells coated with anti- $\alpha$ or anti- $\pi$ GST IgG. A Molecular Devices UV-Max microplate reader capable of 96 simultaneous UV absorbance determinations was employed for GST quantitation. Urinary albumin was quantitated using a radial immunodiffusion assay (The Binding Site, San Diego, CA, USA). Creatinine concentrations were measured using a standard colorimetric procedure (Sigma \#555-A; Sigma-Aldrich, St. Louis, MO, USA). The number of subjects differed between Tables 1,3 and 5 because of variation in the number successful assays for GST $\alpha$, GST $\pi$ and albumin, respectively.

\section{Statistical procedures}

Analyses were performed on log-transformed concentrations, as is common practice for analyzing concentration data, to account for positive skewness and heteroskedasticity (variances increased with increasing mean value). Descriptive statistics were computed for creatinine-adjusted values of GST- $\alpha$, GST- $\pi$, and albumin on the natural logarithm scale by treatment group and year of age. Eight year olds were excluded from age group-specific analyses owing to too few subjects in this age group to permit analysis of associations with statistical significance. Treatment groups were compared across years of age by fitting linear regression models using generalized estimating equations (GEE) (Liang and Zeger, 1986) to account for correlation between measures on the same subject at different ages. Separate regression models were run for each of the three log-transformed concentrations (GST- $\alpha$, GST- $\pi$, and albumin) as outcome variables. The main predictor variable of interest was treatment group (Amalgam versus Composite). The covariates in the models included the log-transformed creatinine concentration in the sample, year of age (9-18) as a categorical variable, the participant's age at baseline in years, participant's gender (female versus male), and participant's race (white versus non-white). Separate analyses were conducted with the baseline values of the outcome variable and log-transformed creatinine as additional covariates to further reduce the error variance and to adjust for group differences at baseline that may have occurred despite the random treatment assignment. Notably, urinary mercury was not included as a predictor variable in the analysis because doing so would deviate from the randomized clinical trail design that allowed us to make inference regarding the causeeffect relationship of amalgam mercury exposure and urinary GST or albumin levels. In this 
respect, our analyses rely on the strength of the randomized design to test for an effect of amalgam exposure on GST and albumin. By comparing groups of children randomly assigned to the different exposures, we avoid confounding of the relationships by other observed or unobserved factors. Associations between observed urinary mercury levels and GST or albumin would provide weaker evidence because they are susceptible to confounding.

\section{RESULTS}

The demographic characteristics of subjects were similar in the two treatment groups, as previously reported (DeRouen et al., 2006). Baseline mean creatinine-adjusted urinary mercury levels were $1.8 \mu \mathrm{grams} / \mathrm{gram}$ creatinine in the amalgam group and $1.9 \mu \mathrm{grams} / \mathrm{gram}$ creatinine in the composite group. Creatinine-adjusted GST- $\alpha$ levels were similar in the two treatment groups and in each gender group in each year of age, as shown in Table 1. Regression analysis, presented in Table 2 (Model I), showed that GST- $\alpha$ levels were approximately 5\% higher in the Amalgam group compared with the Composite group, but this difference was not statistically significant. Females had $11 \%$ higher GST- $\alpha$ levels than males $(\mathrm{p}=0.05)$, and non-whites had about $13 \%$ higher levels than whites $(\mathrm{p}=0.04)$. The gender and race effects became non-significant, however, after adjustment for baseline values (Model II), indicating that differences in GST- $\alpha$ during follow-up based on gender and race can be attributed to differences already present at baseline.

As shown in Table 3, creatinine-adjusted GST- $\pi$ levels tended to increase over the course of the study by 4- to 6- fold from 9 to 18 years of age. This increase was observed in all groups irrespective of treatment or gender. At each age, differences between groups in GST- $\pi$ levels tended to be small and similar to those for GST- $\alpha$. Regression analysis (Table 4) showed that GST- $\pi$ levels were approximately $11 \%$ higher in the Amalgam group overall $(\mathrm{p}=0.04)$ (Model II). Notably, females had GST- $\pi$ levels approximately twice as high as those of males ( $p<0.0001)$. The gender difference was essentially unchanged by adjustment for baseline values (Model II) because of the weak association between baseline and follow-up values of GST- $\pi$. Whites had slightly higher levels than non-whites, and this difference, although small, became significant $(\mathrm{p}=0.025)$ following adjustment for baseline values.

As shown in Table 5, differences between groups in creatinine-adjusted albumin levels were small for all years of age. Albumin levels were slightly lower in the Amalgam group than in the Composite group, but the group effect was not statistically significant in the regression analysis (Table 6). Females had approximately $39 \%$ higher albumin levels than males ( $\mathrm{p}<$ 0.0001). The gender difference was unchanged by adjustment for baseline values (Model II), which is surprising because there was a significant association between baseline and followup values of albumin $(\mathrm{p}<0.001)$, and there was a gender difference in baseline values of albumin of approximately the same magnitude as the difference during follow-up. There was a significant difference between whites and non-whites (with higher levels for whites than non-whites) (Table 6, Model I). However, this difference was reduced and became nonsignificant after adjustment for baseline values (Model II).

Figure 1 provides a graphical representation of changes in creatinine-adjusted GST $\alpha$, GST $\pi$ and albumin by year-of-age and treatment group (left) and by year-of-age and gender (right). This presentation emphasizes the findings of no significant differences in any of these parameters when comparing treatment groups, and shows the progressive increase in GST $\pi$ that occurs between the ages of 9 and 18 in all groups. This figure also shows the significantly greater creatinine-adjusted GST $\pi$ and albumin, but not GST $\alpha$, excreted by females compared with males throughout the course of follow-up from ages 9 through 18 . 
The findings for all parameters described herein were comparable when evaluated as followup year instead of year of age.

\section{DISCUSSION}

Numerous studies have characterized the association of urinary proteins and other cellular constituents with changes in renal tubular integrity associated with disease or nephrotoxicant exposures in both adults and children (de Burbure et al., 2002; Tomlison, 1992;

Trachtenberg and Barregård, 2007). This is the first study to our knowledge to describe urinary GST concentrations in children during the longitudinal course of amalgam treatment from childhood through late adolescence. The findings suggest no deleterious effects of mercury exposure from dental amalgam on either proximal or distal tubule cellular integrity, as indicated by the lack of significant differences in either GST $\alpha$ or $\pi$, respectively, between amalgam and composite groups over a prolonged course of treatment. While other measures of tubular integrity were not evaluated in this study, these findings are consistent with those of Barregard et al., (2008) who reported no changes in alpha-1-microglobulin, $\gamma$-glutamyl transpeptidase or $N$-acetyl- $\beta$-D-glucosaminidase in children participating in the New England Children's Amalgam Trial (NECAT), conducted concurrently with the present study. Comparable findings by de Burbure et al., (2003) suggested that no renal lesions appear to occur in children with mean urinary $\mathrm{Hg}$ levels up to $13.4 \mu \mathrm{g} / \mathrm{g}$ creatinine and a maximum of $25 \mu \mathrm{g} / \mathrm{g}$ creatinine. As previously reported (Woods et al., 2007), the mean peak urinary $\mathrm{Hg}$ concentration observed among children in the present study population was 3.5 $\mu \mathrm{g} / \mathrm{g}$ creatinine.

Of interest is the observation that creatinine-adjusted urinary GST- $\alpha$ concentrations remained relatively constant throughout the course of later childhood and adolescence, whereas urinary GST- $\pi$ increased progressively with age and show substantial gender differences. Although the physiological processes underlying the renal handling of these proteins remain largely unknown, the transcriptional regulation of specific GSTs in humans is understood to be subject to independent arrays of developmental-, sex- and tissue-specific factors (Eaton and Bammler, 1999), possibly accounting for the age- and/or sex-related differences in the expression of GSTs $\alpha$ and $\pi$ observed in this study. While supporting the absence of adverse effects of amalgam mercury exposure on kidney function, these findings are of additional interest in establishing normative values for these measures of proximal and distal tubular integrity, respectively, in children and adolescents.

Although immunologic reactions to mercury are exceedingly rare, mercury-induced autoimmune responses that can lead to glomerulonephritis have been reported (Druet et al., 1982). To this end, we measured urinary albumin concentrations in subjects in the Casa Pia study as an assessment of potential glomerular injury associated with amalgam treatment. As reported in Tables 5 and 6 , we found no significant effects of prolonged amalgam mercury exposure on glomerular integrity as assessed by urinary albumin measurements performed during the course of treatment and follow-up. Similar findings have been reported by other investigators who evaluated urinary albumin excretion in relation to amalgam mercury exposure among healthy human subjects (Herrström et al., 1995; Langworth et al., 1997; Sandborgh-Englund et al., 1996). In contrast, Barregard et al., (2008) reported a significantly higher proportion of children with microalbuminuria (i.e., $>30 \mathrm{mg} / \mathrm{g}$ creatinine) among those receiving dental amalgam treatment compared with those receiving composite resin fillings during the $3^{\text {rd }}$ and $5^{\text {th }}$ years of follow-up in the NECAT study. Using the same metrics (creatinine-adjusted albumin $>30 \mathrm{mg} / \mathrm{gm}$ ) reported therein, in addition to comparison of median urinary albumin values previously reported (DeRouen et al., 2006), our analyses revealed no significant effects of amalgam treatment on the 
proportion of children with microalbuminuria in the present study. These finding are described in Table 7.

In conclusion, we observed no significant effects of dental amalgam mercury on measures of renal tubular or glomerular functional integrity during a prolonged course of dental amalgam treatment in children and adolescents from 9 to 18 years of age. These findings are relevant within the context of children's health risk assessment as relates to the safety of mercury exposure from dental amalgam on kidney function. Additionally, these data provide normative values for sensitive indices of renal functional integrity that may serve in the evaluation of children and adolescents with renal disorders.

\section{Acknowledgments}

The research was funded by Cooperative Agreement U01DE11894 from the National Institute of Dental and Craniofacial Research (NIDCR), National Institutes of Health (NIH). Additional funding was provided by Center grant P30ES07033 and by Superfund Program Project grant P42ES04696 to the University of Washington from the National Institute of Environmental Health Sciences (NIEHS), NIH.

\section{REFERENCES}

Bäckman L, Appelkvist EL, Ringdén O, Dallner G. Glutathione transferase in the urine: A marker for post-transplant tubular lesions. Kidney Int. 1988; 33:571-577. [PubMed: 3283401]

Barregard L, Trachtenberg F, McKinlay S. Renal effects of dental amalgam in children: the New England Children's Amalgam Trial. Environ. Health Perspect. 2008; 116:394-399. [PubMed: 18335109]

Bellinger DC, Trachtenberg F, Barregard L, Tavares M, Cernichiari E, Daniel D, McKinlay S. Neuropsychological and renal effects of dental amalgam in children: A randomized clinical trial. JAMA. 2006; 295:1775-1783. [PubMed: 16622139]

Berglund A, Pohl L, Olsson S, Bergman M. Determination of the rate of release of intra-oral mercury vapor from amalgam. J. Dent. Res. 1988; 67:1235-1242. [PubMed: 3166008]

Bernard A, Lauwerys RR. Proteinuria: Changes and mechanisms in toxic nephropathies. Crit. Rev. Toxicol. 1991; 21:373-405. [PubMed: 1741950]

Brownawell AM, Berent S, Brent RL, Bruckner JV, Doull J, Gershwin EM, Hood RD, Matanoski GM, Rubin R, Weiss B, Karol M,H. The potential adverse health effects of dental amalgam. Toxicol. Rev. 2005; 24:1-10. [PubMed: 16042501]

Campbell JAH, Corrigall AV, Guy A, Kirsh RE. Immunohistologic localization of alpha, mu, and pi class glutatione S-transferases in human tissues. Cancer. 1991; 67:1608-1613. [PubMed: 2001549]

Clarkson TW, Magos L. The toxicology of mercury and its chemical compounds. Crit. Rev. Toxicol. 2006; 36:609-662. [PubMed: 16973445]

Druet P, Bernard A, Hirsch F, Weening JJ, Gengoux P, Mahieu P, Brieland S. Immunologicallymediated glomerulonephritis by heavy metals. Arch. Toxicol. 1982; 50:187-194. [PubMed: 6756345]

DeRouen TA, Leroux BG, Martin MD, Townes BD, Woods JS, Leitão J, Castro-Caldas A, Braveman $\mathrm{N}$. Issues in the design and analysis of a randomized clinical trial to assess the safety of dental amalgam restorations in children. Contr. Clin.Trials. 2002; 23:301-320.

DeRouen TA, Martin MD, Leroux BG, Townes BD, Woods JS, Leitão J, Luis H, Bernardo M, Rosenbaum G, Martins IP. Neurobehavioral effects of dental amalgam in children. JAMA. 2006; 295:1784-1792. [PubMed: 16622140]

Eaton DL, Bammler TK. Concise review of the glutathione S-transferases and their significance to toxicology. Toxicol. Sci. 1999; 49:156-164. [PubMed: 10416260]

Feinfeld, DA.; Sherman, RA.; Safirstein, R.; Ohmi, N.; Fuh, VL.; Arias, IM.; Levine, SD. Urinary ligandin in renal tubular cell injury. In: Bianchi, C.; Bertelli, A.; Duarte, E., editors. Kidney, small proteins and drugs. Contributions to Nephrology. Vol. 42. Karger; Basel: 1984. p. 111-117. 
Halbach S, Clarkson TW. Enzymatic oxidation of mercury vapor by erythrocytes. Biochim. Biophys. Acta. 1978; 523:522-531. [PubMed: 656439]

Harrison DJ, Kharbanda R, Cunningham D. Scott, McLellan LI, Hayes JD. Distribution of glutathione S-transferase isoenzymes in human kidney: Basis for possible markers of renal injury. J. Clin. Pathol. 1989; 42:624-628. [PubMed: 2738168]

Herrström P, Schütz A, Raihle G, Hulthuis N, Högstedt B, Råstam L. Dental amalgam, low-dose exposure to mercury, and urinary proteins in young Swedish men. Arch. Environ. Health. 1995; 50:103-107. [PubMed: 7786045]

Lambers Heerspink HJ, Brinkman JW, Bakker SJL, Gansevoor,t RT, de Zeeuw D. Update on microalbuminuria as a biomarker in renal and cardiovascular disease. Curr. Opin. Nephrol. Hypertens. 2006; 15:631-636. [PubMed: 17053479]

Langworth S, Sällsten G, Barregård L, Cynkier I, Lind M-L, Söderman E. Exposure to mercury vapor and impact on health in the dental profession in Sweden. J. Dent. Res. 1997; 76:1397-1404. [PubMed: 9207773]

Liang K-Y, Zeger SL. Longitudinal data analysis using generalized linear models. Biometrika. 1986; 73:13-22.

Mackert JR Jr. Bergland A. Mercury exposure from dental amalgam fillings: absorbed dose and the potential for adverse health effects. Crit. Rev. Oral. Med. 1997; 8:410-436.

Magos L, Halbach S, Clarkson TW. Role of catalase in the oxidation of mercury vapor. Biochem. Pharmacol. 1978; 27:1373-1377. [PubMed: 567993]

Ohse T, Tanaka T, Ota T, Miyata T, Kojima I, Ingelfinger JR, Ogawa S, Fujita T, Nangaku M. Albumin induces endoplasmic reticulum stress and apoptosis in renal proximal tubular cells. Kidney Int. 2006; 70:1447-1455. [PubMed: 16955111]

Remuzzi G, Bertani T. Pathophysiology of progressive nephropathies. N. Engl. J. Med. 1998; 339:1448-1456. [PubMed: 9811921]

Sandborgh-Englund G, Nygren AT, Ekstrand J, Elinder C-G. No evidence of renal toxicity from amalgam fillings. Amer. J. Physiol. 1996; 40:R91-R945.

Schmidt U, Guder WG. Sites of enzyme activity along the nephron. Kidney Int. 1976; 9:233-242. [PubMed: 940267]

Sundberg AGM, Applekvist E-L, Dallner G, Nilsson R. Glutathione transferases in the urine: Sensitive methods for detection of kidney damage induced by nephrotoxic agents in humans. Environ. Health Perspect. 1994; 102(Suppl 3):293-296. [PubMed: 7843118]

Svare CW, Paterson LC, Reinhardt JW, Boyer DB, Frank CW, Gay DD, et al. The effect of dental amalgam on mercury levels in expired air. J. Dent. Res. 1981; 60:1668-1671. [PubMed: 6943160]

Tomlison PA. Low molecular weight proteins in children with renal disease. Pediatr. Nephrol. 1992; 6:565-571. [PubMed: 1282825]

Trachtenberg F, Barregärd L. The effect of age, sex, and race on urinary markers of kidney damage in children. Amer J. Kidney Dis. 1997; 50:938-945. [PubMed: 18037094]

Vimy MJ, Lorscheider FL. Intra-oral air mercury released from dental amalgam. J. Dent. Res. 1985; 64:1069-1071. [PubMed: 3860538]

Woods, JS. Urinary markers. In: Zalups, RK.; Lash, LH., editors. Methods in Renal Toxicology. CRC Press; Boca Raton: 1996. p. 19-33.

Woods JS, Martin MD, Leroux BG, DeRouen A, Leitão JG, Bernardo MF, Luis HS, Simmonds PL, Kushleika JV, Huang Y. The contribution of dental amalgam to urinary mercury excretion in children. Environ. Health Perspect. 2007; 115:1527-1531. [PubMed: 17938746]

Zalups RK. Molecular interactions with mercury in the kidney. Pharmacol. Rev. 2000; 52:113-143. [PubMed: 10699157]

Zhou Y, Vaidya VS, Brown RP, Zhang J, Rosenzweig BA, Thompson KL, Miller TJ, Bonventre JV, Goering PL. Comparison of kidney injury moledule-1 and other nephrotoxicity biomarkers in urine and kidney following acute exposure to gentamicin, mercury and chromium. Toxicol, Sci. 2008; 101:159-170. [PubMed: 17934191] 
Human Subjects Approval: The study protocol employed in this trial was approved by the institutional review boards at the University of Washington and the University of Lisbon. All parents or guardians gave written consent, and all children provided signed assent. 

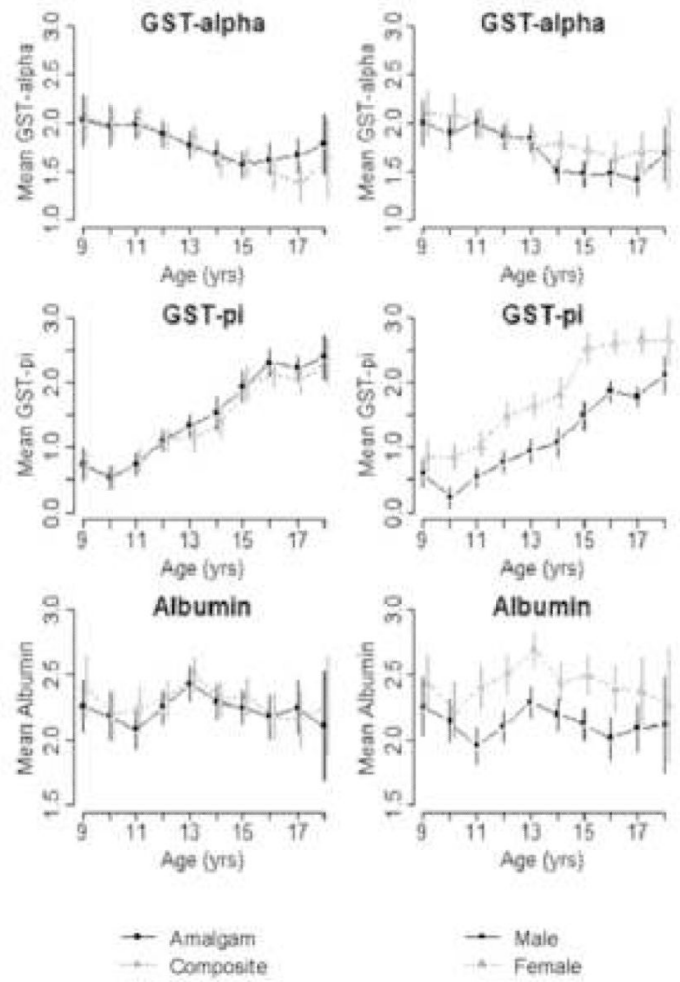

Figure 1.

Urinary concentrations of log-transformed creatinine-adjusted GST- $\alpha$, GST- $\pi$, and Albumin means by age and treatment group (left) or age and gender (right). 


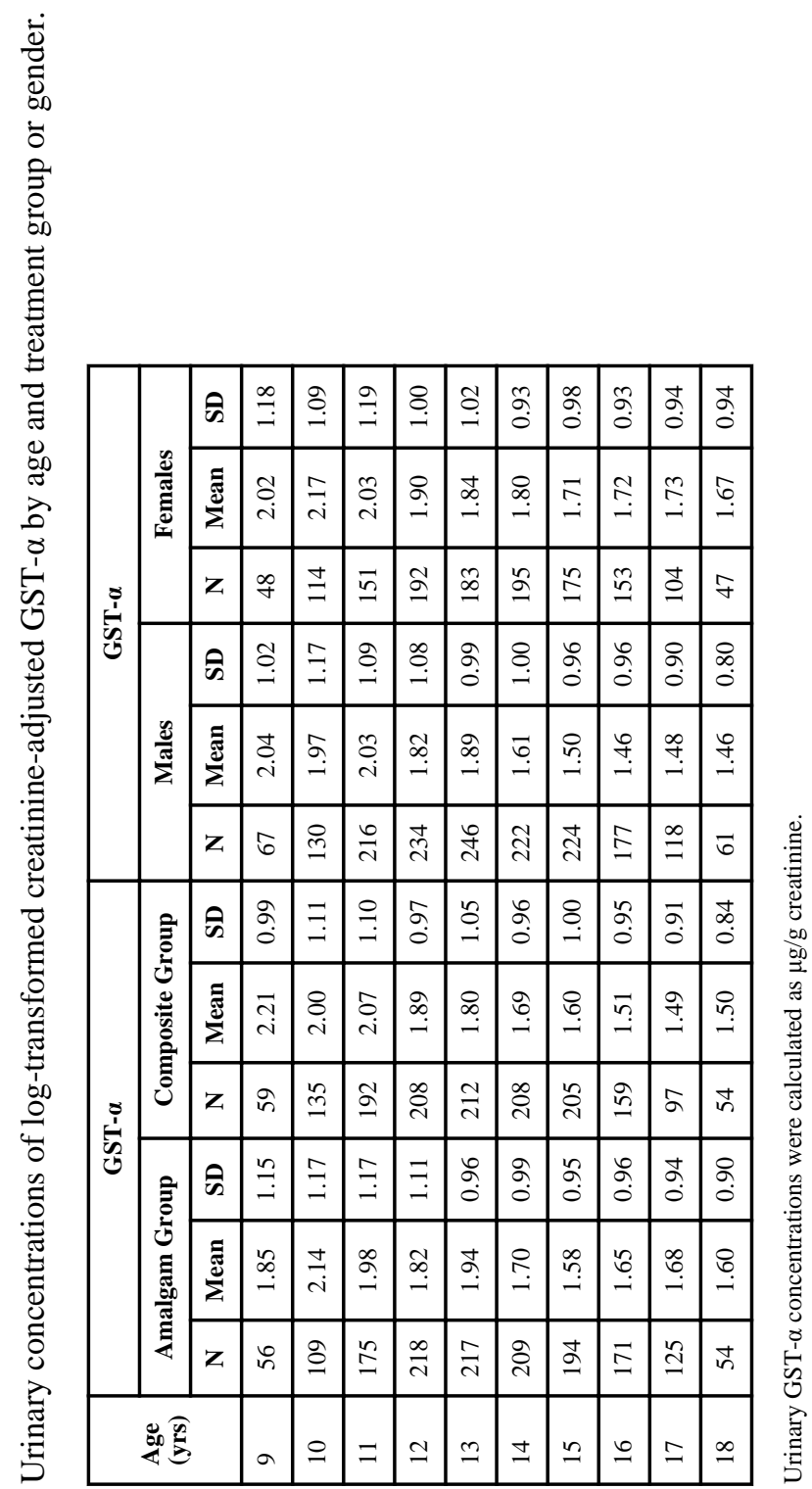


Table 2

Regression analysis of log-transformed GST- $\alpha$ concentrations for ages 9-18.

\begin{tabular}{|c|c|c|c|c|}
\hline \multirow[b]{2}{*}{ Model Term } & \multicolumn{2}{|c|}{ Model I } & \multicolumn{2}{|c|}{ Model II } \\
\hline & $\underset{\text { CI })}{\text { Estimate }^{*}}(95 \%$ & p-value & $\underset{\text { CI })}{\text { Estimate }^{*}(95 \%}$ & p-value \\
\hline \multicolumn{5}{|l|}{ Age: } \\
\hline 9 & $7.08(3.87,12.97)$ & $<0.001$ & $5.36(2.68,10.73)$ & $<0.001$ \\
\hline 10 & $7.08(3.92,12.80)$ & $<0.001$ & $5.53(2.84,10.79)$ & $<0.001$ \\
\hline 11 & $6.28(3.44,11.46)$ & $<0.001$ & $4.88(2.47,9.65)$ & $<0.001$ \\
\hline 12 & $5.91(3.21,10.87)$ & $<0.001$ & $4.75(2.36,9.54)$ & $<0.001$ \\
\hline 13 & $5.72(3.10,10.56)$ & $<0.001$ & $4.38(2.17,8.83)$ & $<0.001$ \\
\hline 14 & $5.30(2.87,9.77)$ & $<0.001$ & $3.94(1.96,7.92)$ & 0.001 \\
\hline 15 & $5.52(2.99,10.19)$ & $<0.001$ & $4.60(2.30,9.19)$ & $<0.001$ \\
\hline 16 & $5.28(2.80,9.94)$ & $<0.001$ & $4.25(2.06,8.77)$ & $<0.001$ \\
\hline 17 & $5.27(2.80,9.93)$ & $<0.001$ & $4.15(2.01,8.59)$ & 0.001 \\
\hline 18 & $5.75(2.93,11.28)$ & $<0.001$ & $4.43(2.03,9.63)$ & 0.002 \\
\hline $\begin{array}{l}\text { Amalgam Group (vs. } \\
\text { Composite) }\end{array}$ & $1.05(0.95,1.17)$ & 0.308 & $1.05(0.94,1.17)$ & 0.405 \\
\hline Female Gender (vs. Male) & $1.11(1.00,1.23)$ & 0.047 & $1.03(0.91,1.15)$ & 0.653 \\
\hline White Race (vs. Non-white) & $0.89(0.79,0.99)$ & 0.035 & $0.96(0.85,1.08)$ & 0.502 \\
\hline Age at baseline (years) & $1.02(0.96,1.08)$ & 0.452 & $1.02(0.95,1.08)$ & 0.642 \\
\hline Log Creatinine (concurrent) & $1.17(1.09,1.25)$ & $<0.001$ & $1.17(1.08,1.27)$ & $<0.001$ \\
\hline Log Creatinine (baseline) & NA & NA & $0.93(0.84,1.04)$ & 0.211 \\
\hline Log GST- $\alpha$ (baseline) & NA & NA & $1.22(1.15,1.29)$ & $<0.001$ \\
\hline
\end{tabular}

exponentiated

Models I and II represent regressions performed before and after adjustment for baseline values, respectively 
.

๓

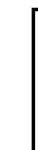
?

s

\begin{tabular}{|c|c|c|c|c|c|c|c|c|c|c|c|c|}
\hline & & के & $\cong$ & $\stackrel{g}{\stackrel{g}{+}}$ & $\stackrel{\leftrightarrow}{\stackrel{\rho}{\circ}}$ & $\stackrel{\vartheta}{\leftrightarrows}$ & $\stackrel{t}{\stackrel{t}{+}}$ & $\stackrel{\sigma}{-}$ & $\stackrel{\bullet}{\stackrel{\circ}{-}}$ & $\mid \begin{array}{l}0 \\
0 \\
0\end{array}$ & $\bar{\sigma}$ & $\mid \begin{array}{l}\infty \\
0 \\
0\end{array}$ \\
\hline & 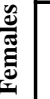 & ⿷匚 & $\begin{array}{l}\vec{\infty} \\
0 \\
0\end{array}$ & $\begin{array}{l}\stackrel{0}{\infty} \\
\stackrel{0}{0}\end{array}$ & ô. & తి & $\stackrel{2}{2}$ & $\stackrel{t}{\stackrel{t}{-}}$ & $\underset{\sim}{\stackrel{\sim}{i}}$ & $\begin{array}{l}\stackrel{\sigma}{S} \\
\text { i }\end{array}$ & $\hat{n}$ & 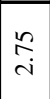 \\
\hline & & $\mathrm{z}$ & $\stackrel{\infty}{+}$ & $\Xi$ & $\cong$ & $\hat{n}$ & $\stackrel{m}{m}$ & 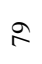 & $\stackrel{\infty}{\sim}$ & $\infty$ & $\approx$ & $\bar{n}$ \\
\hline & \multirow{3}{*}{$\frac{\frac{\tilde{v}}{\pi}}{\frac{\pi}{\Sigma}}$} & के & $\stackrel{5}{-}$ & $\stackrel{8}{-}$ & $\stackrel{t}{\stackrel{t}{-}}$ & $\stackrel{\&}{-}$ & $\cong$ & बे & $\begin{array}{l}\infty \\
\stackrel{0}{0}\end{array}$ & $\left|\begin{array}{l}\infty \\
\infty \\
0 \\
0\end{array}\right|$ & $\begin{array}{l}\infty \\
\infty \\
0\end{array}$ & 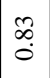 \\
\hline & & 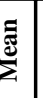 & $\stackrel{\overbrace{}}{\circ}$ & $\tilde{\widetilde{o}}$ & fo & $\stackrel{8}{\circ}$ & $\begin{array}{l}\infty \\
\stackrel{\infty}{0}\end{array}$ & à & $\stackrel{\mathcal{F}}{-}$ & $\stackrel{?}{\stackrel{0}{-}}$ & $\underset{-}{-\infty}$ & $\bar{\Omega}$ \\
\hline & & $\mathrm{z}$ & $\stackrel{\infty}{n}$ & $\stackrel{t}{0}$ & 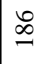 & 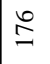 & 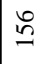 & $\nsubseteq$ & $\infty$ & 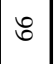 & $£$ & 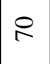 \\
\hline & \multirow{3}{*}{ 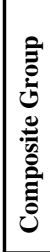 } & के & $\stackrel{\overbrace{}}{\leftarrow}$ & $\stackrel{\vec{\sigma}}{-}$ & $\exists$ & $\stackrel{ \pm}{\Xi}$ & הิ & $\exists$ & $\stackrel{9}{\leftrightarrows}$ & $\hat{a}$ & $\bar{\sigma}$ & $\stackrel{8}{\circ}$ \\
\hline & & 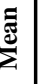 & $\begin{array}{l}\stackrel{0}{\circ} \\
\stackrel{0}{\circ}\end{array}$ & 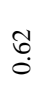 & $\underset{0}{\mathbb{O}}$ & $\bar{\sigma}$ & $\stackrel{\bigcirc}{\leftrightarrows}$ & $\stackrel{\Xi}{\text { I }}$ & $\stackrel{尺}{i}$ & $\frac{n}{i}$ & $\underset{\sim}{\stackrel{\sim}{\sim}}$ & $\overrightarrow{\mathrm{N}}$ \\
\hline & & $\mathrm{z}$ & $\vec{n}$ & $\Xi$ & $\underline{6}$ & 志 & 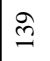 & 8 & $\alpha$ & 8 & $\infty$ & 8 \\
\hline & & के & $\cong$ & $\stackrel{ְ}{=}$ & 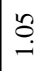 & $\stackrel{\vartheta}{=}$ & $\underset{\sim}{\Delta}$ & $\stackrel{\overbrace{}}{\stackrel{\overbrace{}}{-}}$ & $\stackrel{?}{\stackrel{\leftrightarrow}{-}}$ & $\bar{a}$ & $\hat{\sigma}$ & gे \\
\hline & ב్ & 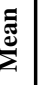 & : & है & $\stackrel{\vec{b}}{\circ}$ & $\begin{array}{c}\hat{\infty} \\
0 \\
0\end{array}$ & 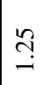 & $\stackrel{\infty}{\dddot{m}}$ & $\stackrel{?}{=}$ & 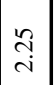 & $\begin{array}{l}\hat{ત} \\
\text { in }\end{array}$ & $\ddot{\overbrace{}}$ \\
\hline & 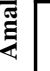 & $\mathbf{z}$ & in & $\stackrel{t}{\underline{O}}$ & $\Xi$ & $\stackrel{n}{6}$ & $\cong$ & $\infty$ & $\approx$ & 8 & g & 5 \\
\hline & & & & & $=$ & $\simeq$ & 2 & \pm & $\because$ & $\because$ & $=$ & $\stackrel{\infty}{\sim}$ \\
\hline
\end{tabular}


Table 4

Regression analysis of log-transformed GST- $\pi$ concentrations for ages 9-18.

\begin{tabular}{|c|c|c|c|c|}
\hline \multirow[b]{2}{*}{ Model Term } & \multicolumn{2}{|l|}{ Model I } & \multicolumn{2}{|l|}{ Model II } \\
\hline & $\underset{\text { CI })}{\text { Estimate }^{*}(95 \%}$ & p-value & $\underset{\text { CI })}{\text { Estimate }^{*}(95 \%}$ & p-value \\
\hline \multicolumn{5}{|l|}{ Age: } \\
\hline 9 & $10.06(4.85,20.84)$ & $<0.001$ & $7.99(3.21,19.88)$ & $<0.001$ \\
\hline 10 & $10.95(5.34,22.45)$ & $<0.001$ & $8.17(3.40,19.64)$ & $<0.001$ \\
\hline 11 & $14.59(7.04,30.22)$ & $<0.001$ & $11.01(4.55,26.64)$ & $<0.001$ \\
\hline 12 & $19.54(9.10,41.94)$ & $<0.001$ & $15.05(5.96,37.96)$ & $<0.001$ \\
\hline 13 & $24.13(11.18,52.10)$ & $<0.001$ & $20.07(7.93,50.78)$ & $<0.001$ \\
\hline 14 & $29.59(13.73,63.76)$ & $<0.001$ & $22.68(8.86,58.03)$ & $<0.001$ \\
\hline 15 & $45.30(21.96,93.48)$ & $<0.001$ & $35.44(14.77,85.06)$ & $<0.001$ \\
\hline 16 & $\begin{array}{c}65.10(30.87 \\
137.33)\end{array}$ & $<0.001$ & $\begin{array}{c}50.47(20.57 \\
123.78)\end{array}$ & $<0.001$ \\
\hline 17 & $\begin{array}{l}71.74(32.67 \\
157.50)\end{array}$ & $<0.001$ & $\begin{array}{l}57.49(22.42 \\
\quad 147.42)\end{array}$ & $<0.001$ \\
\hline 18 & $\begin{array}{l}93.20(41.08 \\
211.45)\end{array}$ & $<0.001$ & $\begin{array}{l}66.84(25.05 \\
178.34)\end{array}$ & $<0.001$ \\
\hline $\begin{array}{l}\text { Amalgam Group (vs. } \\
\text { Composite) }\end{array}$ & $1.08(0.96,1.20)$ & 0.203 & $1.11(0.98,1.26)$ & 0.091 \\
\hline Female Gender (vs. Male) & $2.04(1.83,2.29)$ & $<0.001$ & $2.01(1.78,2.28)$ & $<0.001$ \\
\hline White Race (vs. Non-white) & $1.11(0.98,1.26)$ & 0.105 & $1.17(1.02,1.34)$ & 0.025 \\
\hline Age at baseline (years) & $0.81(0.76,0.87)$ & $<0.001$ & $0.83(0.76,0.90)$ & $<0.001$ \\
\hline Log Creatinine (concurrent) & $1.75(1.59,1.93)$ & $<0.001$ & $1.81(1.63,2.02)$ & $<0.001$ \\
\hline Log Creatinine (baseline) & NA & NA & $0.98(0.87,1.09)$ & 0.689 \\
\hline Log GST- $\pi$ (baseline) & NA & NA & $1.03(0.97,1.10)$ & 0.353 \\
\hline
\end{tabular}




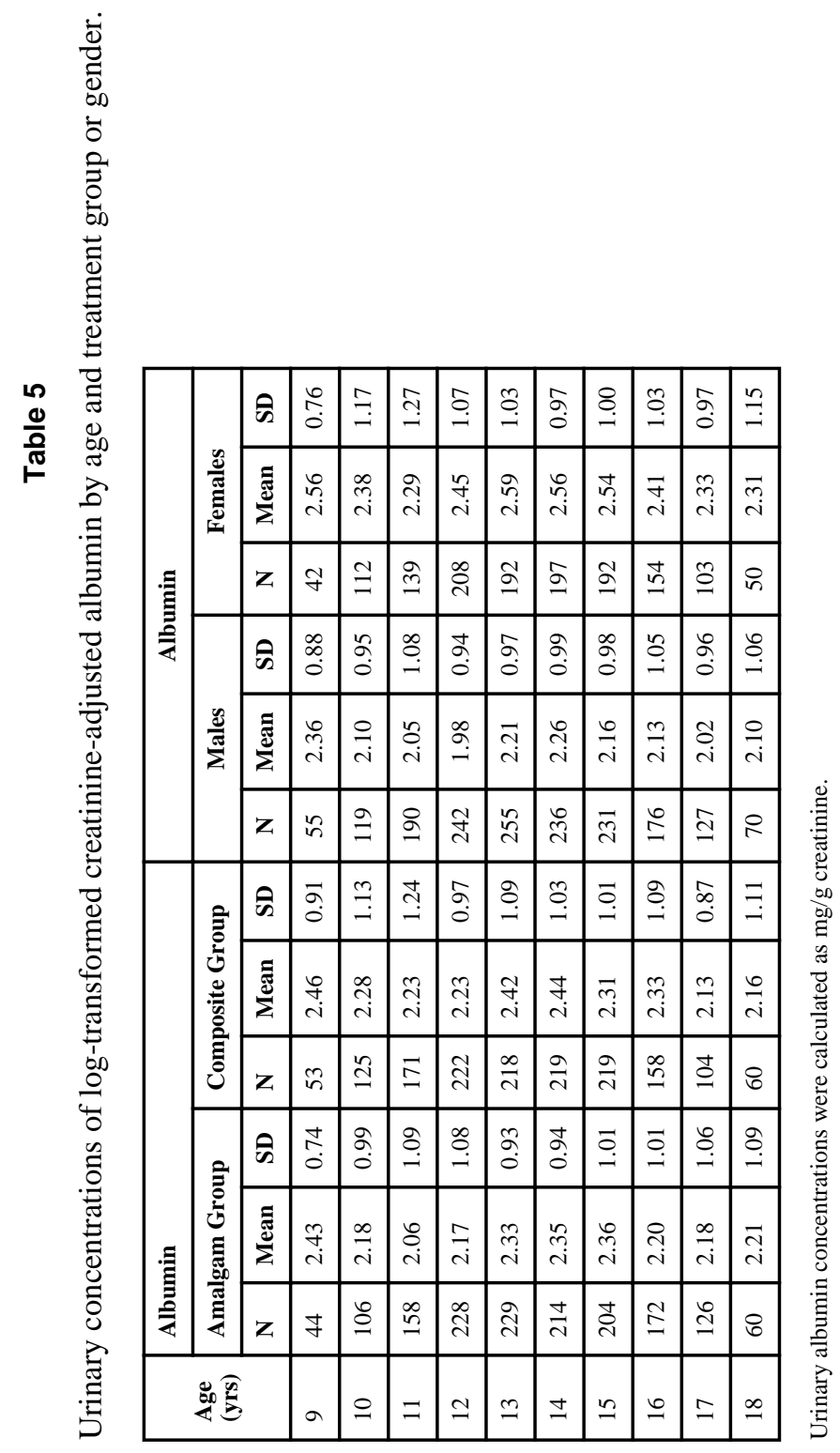


Table 6

Regression analysis of log-transformed urinary albumin concentrations for ages 9-18.

\begin{tabular}{|c|c|c|c|c|}
\hline \multirow[b]{2}{*}{ Model Term } & \multicolumn{2}{|l|}{ Model I } & \multicolumn{2}{|l|}{ Model II } \\
\hline & $\underset{\text { CI) }}{\text { Estimate }^{*}(95 \%}$ & p-value & $\begin{array}{l}\text { Estimate }{ }^{*}(95 \% \\
\text { CI) }\end{array}$ & p-value \\
\hline \multicolumn{5}{|l|}{ Age: } \\
\hline 9 & $9.55(4.74,19.27)$ & $<0.001$ & $4.33(1.70,10.99)$ & 0.002 \\
\hline 10 & $7.88(3.75,16.54)$ & $<0.001$ & $4.08(1.52,10.94)$ & 0.005 \\
\hline 11 & $7.90(3.81,16.41)$ & $<0.001$ & $4.21(1.63,10.89)$ & 0.003 \\
\hline 12 & $9.69(4.67,20.15)$ & $<0.001$ & $5.10(1.95,13.29)$ & 0.001 \\
\hline 13 & $11.88(5.67,24.88)$ & $<0.001$ & $6.32(2.40,16.66)$ & $<0.001$ \\
\hline 14 & $10.34(4.94,21.64)$ & $<0.001$ & $5.45(2.08,14.27)$ & 0.001 \\
\hline 15 & $10.52(4.99,22.18)$ & $<0.001$ & $5.25(2.00,13.74)$ & 0.001 \\
\hline 16 & $9.61(4.51,20.48)$ & $<0.001$ & $5.15(1.89,14.01)$ & 0.001 \\
\hline 17 & $10.14(4.75,21.65)$ & $<0.001$ & $5.03(1.85,13.66)$ & 0.002 \\
\hline 18 & $9.62(4.26,21.72)$ & $<0.001$ & $4.51(1.49,13.66)$ & 0.008 \\
\hline $\begin{array}{l}\text { Amalgam Group (vs. } \\
\text { Composite) }\end{array}$ & $0.92(0.82,1.04)$ & 0.179 & $0.91(0783,1.07)$ & 0.274 \\
\hline Female Gender (vs. Male) & $1.38(1.22,1.56)$ & $<0.001$ & $1.39(1.18,1.63)$ & $<0.001$ \\
\hline White Race (vs. Non-white) & $1.16(1.02,1.32)$ & 0.023 & $1.10(0.94,1.28)$ & 0.229 \\
\hline Age at baseline (years) & $0.97(0.90,1.03)$ & 0.311 & $0.98(0.90,1.06)$ & 0.556 \\
\hline Log Creatinine (concurrent) & $2.13(1.90,2.37)$ & $<0.001$ & $2.25(1.97,2.56)$ & $<0.001$ \\
\hline Log Creatinine (baseline) & NA & NA & $0.77(0.62,0.96)$ & 0.020 \\
\hline Log albumin (baseline) & NA & NA & $1.29(1.15,1.45)$ & $<0.001$ \\
\hline
\end{tabular}

exponentiated 
Table 7

Creatinine-adjusted urinary albumin by treatment group for creatinine $>30 \mathrm{mg} / \mathrm{gm}$ creatinine.

\begin{tabular}{|l|l|l|c|c|}
\hline \multicolumn{6}{|c|}{ Albumin/creatinine > 30 during follow up } \\
\hline Age & $\begin{array}{l}\text { Amalgam } \\
\text { events / visits }\end{array}$ & $\begin{array}{l}\text { Composite } \\
\text { events / visits }\end{array}$ & $\begin{array}{c}\text { Odds Ratio } \\
(\text { amal/comp })\end{array}$ & p-value \\
\hline 9 & $3 / 32$ & $5 / 37$ & 0.7 & 0.72 \\
\hline 10 & $4 / 95$ & $13 / 107$ & 0.3 & 0.52 \\
\hline 11 & $12 / 182$ & $15 / 178$ & 0.8 & 0.69 \\
\hline 12 & $21 / 231$ & $26 / 230$ & 0.8 & 0.67 \\
\hline 13 & $33 / 235$ & $37 / 229$ & 0.8 & 0.70 \\
\hline 14 & $22 / 206$ & $26 / 224$ & 0.9 & 0.78 \\
\hline 15 & $18 / 197$ & $33 / 211$ & 0.5 & 0.52 \\
\hline 16 & $17 / 158$ & $17 / 132$ & 0.8 & 0.72 \\
\hline 17 & $14 / 103$ & $8 / 83$ & 1.5 & 0.66 \\
\hline 18 & $3 / 30$ & $3 / 29$ & 1.0 & 0.83 \\
\hline
\end{tabular}

Wald tests were used to test for a difference in the log odds of albumin/creatinine $>30$ (odds ratio different from 1 ) at each age during follow-up. 